\title{
Inhibin A as a tumor marker for primary bilateral macronodular adrenal hyperplasia
}

\author{
Rachel Wurth', Crystal Kamilaris', Naris Nilubol'2, Samira M Sadowski², \\ Annabel Berthon', Martha M Quezado ${ }^{3}$, Fabio R Faucz'1, Constantine A Stratakis ${ }^{1}$ and \\ Fady Hannah-Shmouni ${ }^{1}$
}

1Section on Endocrinology and Genetics, Eunice Kennedy Shriver National Institute of Child Health and Human Development, 2 Surgical Oncology, National Cancer Institute, National Institutes of Health, Bethesda, Maryland, USA, and 3 Laboratory of Pathology Center for Cancer Research, National Cancer Institute, National Institutes of Health, Bethesda, Maryland, USA
Correspondence should be addressed to F Hannah-Shmouni Email

fady.hannah-shmouni@nih. gov

\section{Summary}

Primary bilateral macronodular adrenal hyperplasia (PBMAH) is a rare cause of ACTH-independent Cushing syndrome (CS). This condition is characterized by glucocorticoid and/or mineralocorticoid excess, and is commonly regulated by aberrant G-protein coupled receptor expression may be subclinical, allowing the disease to progress for years undetected. Inhibin $A$ is a glycoprotein hormone and tumor marker produced by certain endocrine glands including the adrenal cortex, which has not been previously investigated as a potential tumor marker for PBMAH. In the present report, serum inhibin A levels were evaluated in three patients with PBMAH before and after adrenalectomy. In all cases, serum inhibin A was elevated preoperatively and subsequently fell within the normal range after adrenalectomy. Additionally, adrenal tissues stained positive for inhibin A. We conclude that serum inhibin A levels may be a potential tumor marker for PBMAH.

\section{Learning points:}

- PBMAH is a rare cause of CS.

- PBMAH may have an insidious presentation, allowing the disease to progress for years prior to diagnosis.

- Inhibin A is a heterodimeric glycoprotein hormone expressed in the gonads and adrenal cortex.

- Inhibin A serum concentrations are elevated in some patients with PBMAH, suggesting the potential use of this hormone as a tumor marker.

- Further exploration of serum inhibin A concentration, as it relates to PBMAH disease progression, is warranted to determine if this hormone could serve as an early detection marker and/or predictor of successful surgical treatment.

\section{Background}

Cushing syndrome (CS) results from prolonged and inappropriately high glucocorticoid exposure and is comprised of an aggregate of signs and symptoms. These may include fatigue, weight gain, decreased concentration, mood disturbance, insomnia, decreased libido, menstrual irregularities, dorsocervical and supraclavicular fat deposition, facial rounding, hirsutism, acne, thin skin and poor skin healing, and more specifically easy bruising, facial plethora, proximal myopathy, and striae, among others $(1,2,3)$. Patients with CS may develop hypertension, osteoporosis, type 2 diabetes mellitus, hypokalemia, nephrolithiasis, and unusual infections. Approximately $20 \%$ of cases of CS are ACTH-independent and are due to primary adrenal disease, with $10-15 \%$ of these cases arising from bilateral adrenocortical hyperplasia (3). Primary bilateral 
macronodular adrenal hyperplasia (PBMAH) is a rare cause of ACTH-independent CS, accounting for less than $1 \%$ of cases, which is characterized by bilateral adrenocortical hyperplasia with nodules larger than $1 \mathrm{~cm}$ in diameter (2). This disease is most often sporadic, but is inherited in an autosomal dominant manner when hereditary. Rarely, it is a component of multiple tumor syndormes such as familial adenomatous polyposis, multiple endocrine neoplasia type 1 , or hereditary leiomyomatosis and renal cell carcinoma. Amongst other defects, abberant G-protein-coupled receptor (GPCR) expression, diseasecausing variants in ARMC5, dysregulation of the cyclic AMP-protein kinase A (PKA) signaling pathway, and intra-nodular or ectopic ACTH secretion have been implicated in the pathogenesis of PBMAH $(1,2,3,4$, 5). Typically, PBMAH leads to subclinical glucocorticoid and/or mineralocorticoid excess, though excess estrogen or androgen production have also been described $(2,6)$. PBMAH is often diagnosed at an older age (between 40 and 60 years of age) and has an insidious clinical course with atypical CS over many years, though severe CS may occasionally develop $(2,7)$.

Inhibins are heterodimeric glycoprotein hormones that exist as two isoforms, inhibin $\mathrm{A}$ and inhibin $\mathrm{B}$, and are members of the transforming growth factor-beta (TGF- $\beta$ ) family of growth and differentiation factors. Each glycoprotein consists of an alpha and beta subunit, with the beta subunit dictating the class as either inhibin A or B (8). Inhibins have been well characterized as hormones produced by the gonads that participate in the regulation of follicle stimulating hormone (FSH) production from the anterior pituitary. In addition, inhibin A is used as a tumor marker for granulosa cell tumors of the ovaries $(9,10)$. Interestingly, several studies have shown that inhibin A is produced by the adrenal cortex, with one previously published study demonstrating elevated serum concentrations of inhibin A in a patient with PBMAH (8, $11,12)$. We report three cases of patients with PBMAH that had elevated serum concentrations of inhibin A at diagnosis and normalization of serum inhibin A after treatment with adrenalectomy.

\section{Case presentation}

\section{Clinical case 1}

A 51-year-old Caucasian male with type 1 diabetes mellitus presented with worsening hyperglycemia and signs and symptoms of CS (12). Additionally, he had facial telengectasia, gynecomastia, and low testicular volume
$(<10 \mathrm{cc})$. Laboratory testing revealed elevated urinary free cortisol (UFC), 17-hydroxysteroids (17OHS), undetectable $\mathrm{ACTH}$, and central hypogonadism. Serum inhibin A concentration was $5.5 \mathrm{pg} / \mathrm{mL} \quad(<2.0 \mathrm{pg} / \mathrm{mL})$. Given the clinical features suggestive of estrogen excess, he underwent a 6-day Liddle test, which did not demonstrate suppression of estrone, estradiol, UFC, or 17OHS. He was diagnosed with ACTH-independent CS with glucocorticoid and estrogen excess. Adrenal imaging with CT was consistent with PBMAH (Fig. 1) (12). The patient underwent bilateral adrenalectomy with undetectable postoperative serum inhibin A. Pathology was consistent with macronodular hyperplasia, with positive staining for inhibin A (Fig. 2). He screened positive for a diseasecausing germline variant in ARMC5 (c.517C>T, p.R173*).

\section{Clinical case 2}

A 47-year-old African American female presented with clinical features of CS and complaints of weight gain, secondary amenorrhea, uncontrolled type 2 diabetes mellitus, and easy bruising. Evaluations for CS demonstrated hypercortisolemia with suppressed ACTH. Her serum inhibin A concentration was $4.9 \mathrm{pg} /$ $\mathrm{mL}(<2.1 \mathrm{pg} / \mathrm{mL})$. Adrenal CT revealed nodules on both adrenal glands measuring $2.3 \mathrm{~cm}$ on the left and $3.6 \mathrm{~cm}$ on the right, consistent with PBMAH (Fig. 1). The patient underwent bilateral adrenalectomy for treatment of CS, with undetectable inhibin A following surgery. Pathology was consistent with macronodular hyperplasia, with positive staining for inhibin A (Fig. 3). She screened positive for a disease-causing germline variant in ARMC5 (c.1084C>T, p.A362T).

\section{Clinical case 3}

A 58-year-old Asian male without clinical features of CS was incidentally found to have bilateral adrenal nodules on abdominal imaging. Biochemical evaluation for hypercortisolemia was consistent with subclinical CS. Serum inhibin A concentration was $2.4 \mathrm{pg} / \mathrm{mL}(<2.0$ $\mathrm{pg} / \mathrm{mL}$ ). Adrenal CT revealed nodules on both adrenal glands measuring $3.2 \times 2.6 \mathrm{~cm}$ on the left and $4.8 \times 3.9$ $\mathrm{cm}$ on the right, consistent with PBMAH (Fig. 1). The patient underwent unilateral right adrenalectomy for the treatment of subclinical CS. Serum inhibin A was undetectable postoperatively. Pathology was consistent with macronodular hyperplasia, with positive staining for inhibin A (Fig. 4). He screened negative for ARMC5 genetic defects. 

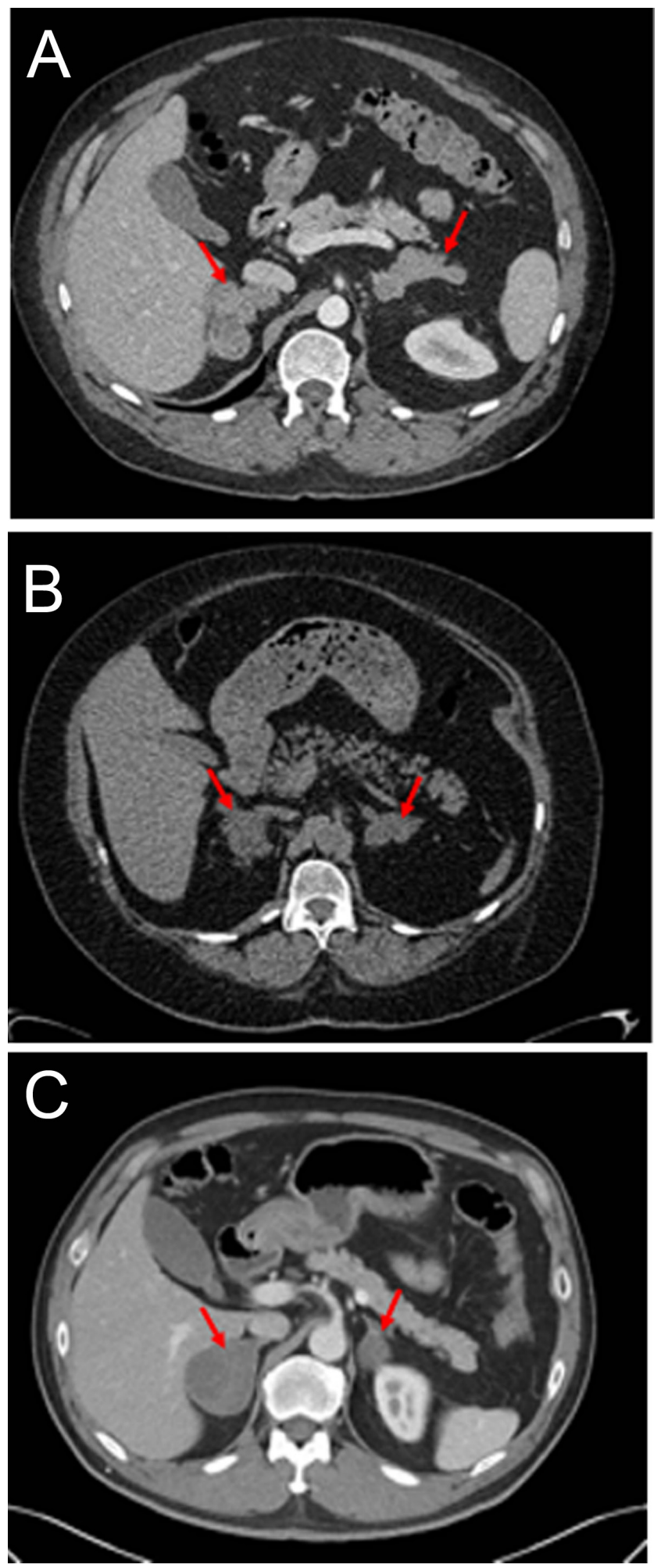

Figure 1

Adrenal computed tomography (CT) images from cases 1 (A), 2 (B), and 3 (C), consistent with macronodular adrenocortical hyperplasia.

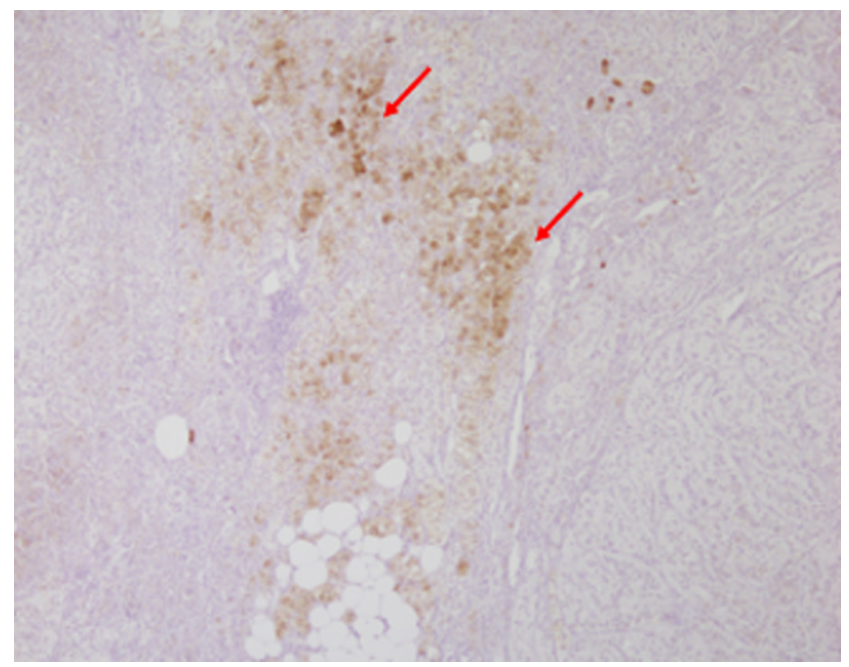

\section{Figure 2}

Immunohistochemistry for inhibin A expression from case 1. Staining was performed on the resected adrenal glands showing patchy staining for inhibin A (magnification $4 \times$ ).

\section{Investigation}

All patients underwent screening and confirmatory testing for CS as outlined by the Endocrine Society's Clinical Practice Guideline (13). Preoperatively, imaging of the adrenal glands was performed with adrenal CT. The serum inhibin A concentration was measured pre- and post-adrenalectomy.

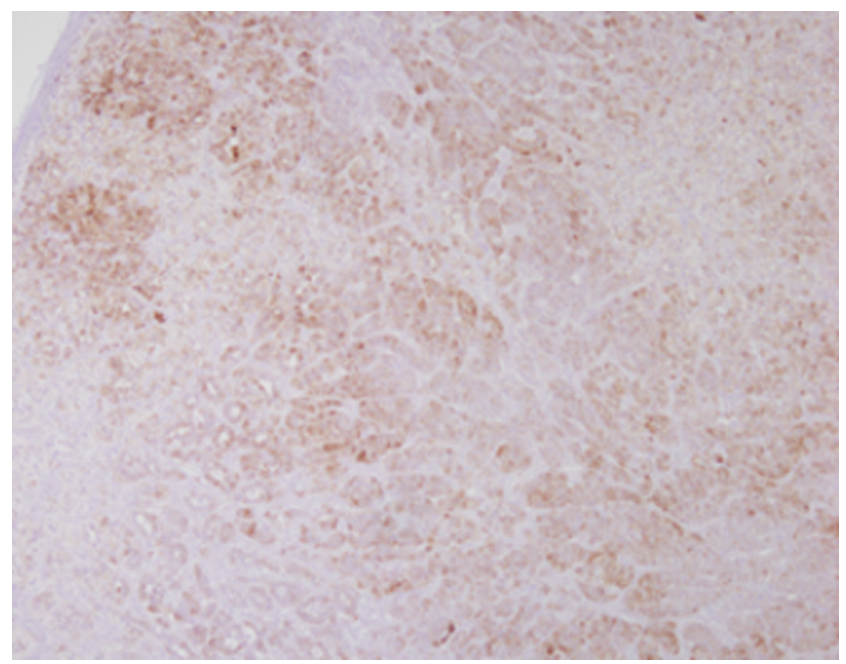

Figure 3

Immunohistochemistry for inhibin A expression from case 2. Staining was performed on the resected adrenal glands showing abundant inhibin A staining with many foci (magnification $4 \times$ ). 


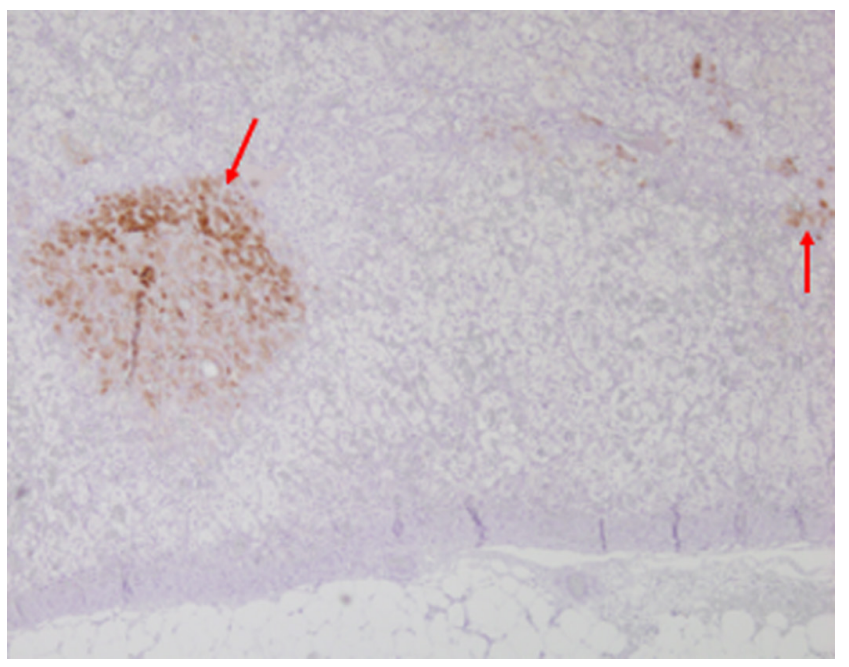

\section{Figure 4}

Immunohistochemistry for inhibin A expression from case 3. Staining was performed on the resected adrenal gland showing patchy staining for inhibin A (magnification 4×).

\section{Treatment}

The patients in case 1 and 2 had overt CS and underwent bilateral adrenalectomy given the severity of their hypercortisolemia. The patient in case 3 underwent right unilateral adrenalectomy of the larger gland in the setting of subclinical CS.

\section{Outcome and follow-up}

In case 1, surgical resection successfully ameliorated the patient's hypercortisolemia and hyperestronemia and serum inhibin A was undetectable, as expected for healthy males (Table 1) (6). In case 2, following bilateral adrenalectomy, the patient had resolution of clinical and biochemical evidence of CS and serum inhibin A levels normalized (Table 1 ). In case 3 , following unilateral right adrenalectomy, serum inhibin A was undetectable. (Table 1).

\section{Discussion}

In this report, we describe three cases of patients with PBMAH and clinical and/or biochemical evidence of hypercortisolemia, who had elevated serum inhibin A concentration at the time of diagnosis, with subsequent decline in serum inhibin A concentration after adrenalectomy for the treatment of CS.

The diagnosis of PBMAH is based on the presence of ACTH-independent hypercortisolemia and bilateral adrenal macronodules on imaging (3). However, several aspects of this disease may delay a timely diagnosis. Hypercortisolemia is often subclinical and detection of large adrenal nodules on imaging is not specific to PBMAH but a characteristic shared with other primary adrenal diseases, including bilateral non-functioning adrenal adenomas $(3,14)$. Sensitive and specific markers for the detection and diagnosis of PBMAH are required to mitigate the deleterious consequences of delayed diagnosis.

The standard of care for the treatment of PBMAH with overt CS is bilateral adrenalectomy; however, unilateral adrenalectomy may be considered for milder cases of hypercortisolemia. In rare cases, pharmacological agents have been employed to target hypersteroidemia in patients with PBMAH and ectopic GPCR expression as an alternative to surgical treatment (4). Such examples include the use of $\beta$-blockers for PBMAH with ectopic expression of the $\beta$-adrenergic receptor or the use of

Table 1 Summary of cases.

\begin{tabular}{|c|c|c|c|c|c|c|}
\hline \multirow[b]{2}{*}{ Case } & \multirow[b]{2}{*}{ Age (years) } & \multirow[b]{2}{*}{ Sex } & \multirow[b]{2}{*}{ Pathology } & \multirow[b]{2}{*}{ ARMC5 } & \multicolumn{2}{|c|}{ Inhibin A $(\mathrm{pg} / \mathrm{mL})^{\mathbf{1}}$} \\
\hline & & & & & Pre-surgery & Post-surgery \\
\hline 1 & 51 & Male & $\begin{array}{l}\text { Multinodular adrenocortical hyperplasia } \\
\text { of the adrenal cortex consistent with } \\
\text { PBMAH. }\end{array}$ & c.517C>T, p.R173* & 5.5 & $<1.0$ \\
\hline 2 & 47 & Female & $\begin{array}{l}\text { Multinodular adrenocortical hyperplasia } \\
\text { of the adrenal cortex consistent } \\
\text { with PBMAH. }\end{array}$ & c. $1084 C>T$, p.A362T & 4.9 & $<2.0$ \\
\hline 3 & 58 & Male & $\begin{array}{l}\text { Multinodular adrenocortical hyperplasia } \\
\text { of the adrenal cortex consistent } \\
\text { with PBMAH. }\end{array}$ & Negative & 2.4 & $<2.0$ \\
\hline
\end{tabular}

The reference ranges for serum inhibin A are as follows: males: $<2.0$ pg/mL; postmenopausal female: $<2.1$ pg/mL; pre-menopausal female without secondary amenorrhea: $<97.5 \mathrm{pg} / \mathrm{mL}$. Values in bold are above the reference range.

*indicates a change to a stop codon; ${ }^{1}$ This test was performed by Mayo Clinic in a manner consistent with CLIA requirements. The testing method is an immunoenzymatic assay manufactured by Beckman Coulter Inc. and performed on the UniCel DxI 800. 
GnRH agonists in the setting of abarrent $\mathrm{LH} / \mathrm{hCG}$ receptor expression $(12,15)$.

Inhibins have a diverse mechanism of action but most commonly antagonize activins within the hypothalamuspituitary-gonadal (HPG) axis, ultimately down-regulating the secretion of FSH. Additionally, inhibins are antagonists of TGF- $\beta$ ligands, which are involved in the regulation of cell growth, among other functions. Accordingly, the inhibin $\alpha$-subunit has been implicated in adrenal tumorigenesis in mice. Currently, a precursor subunit of inhibin, inhibin pro- $\alpha \mathrm{C}$, has been proposed as a tumor marker for adrenocortical carcinoma (15).

In our three cases, serum inhibin A concentration was elevated at the time of diagnosis of PBMAH. Following bilateral or unilateral adrenalectomy, the serum inhibin A concentration declined below the detectable limit of our laboratory assay. In cases 1 and 3, inhibin A was inappropriately elevated in a male patient. In case 2 , secondary amenorrhea from hypercortisolaemia should have suppressed the production of inhibin A from the ovaries. Since inhibin A is regulated by gonadotrophins (FSH, LH), elevated serum inhibin A should be interpreted with caution in pre-menopausal patients with secondary amenorrhea. It is also important to note that expression profiles of inhibins vary across ages and genders, with postmenopausal women only expressing inhibin pro$\alpha \mathrm{C}$ (15). Additionally, immunohistochemical analysis revealed positive staining for inhibin A across all cases (Figs 2, 3 and 4). Interestingly, both patients that presented with PBMAH and severe CS had disease-causing variants in ARMC5.

These data support that inhibin A may be a tumor marker for PBMAH, with a decline in inhibin A being an indicator of successful surgical treatment. Hofland et al. measured serum inhibin A concentrations in patients with adrenocortical adenomas, adrenocortical carcinomas, adrenocortical hyperplasia, and non-adrenocortical neoplasms. Across all groups, none of the patients had elevated inhibin A levels (reference range $<10 \mathrm{pg} / \mathrm{mL}$ ). Three patients with adrenocortical hyperplasia were diagnosed with ACTH-independent macronodular adrenal hyperplasia (AIMAH), a term previously used to describe PBMAH (15). The use of different assays to measure inhibin A concentration, and subsequently different reference ranges, may explain discrepancies in our findings. Further analysis of inhibin expression, as it relates to age, gender, and disease progression, will be required to holistically evaluate the utility of inhibin A as a tumor marker. Additionally, the link between ARMC5 and inhibin A should be explored in future studies.

\section{Declaration of interest}

Constantine A Stratakis holds patents on the PRKAR1A, PDE11A, and GPR101 genes and his laboratory is the recipient of past and ongoing research grant support from Pfizer Inc. Fabio R Faucz holds patent on the GPR101 gene. The other authors have nothing to disclose.

\section{Funding}

This work was supported by the research project Z01-HD008920 (Principal Investigator: Constantine A. Stratakis) of the Intramural Research Program of the Eunice Kennedy Shriver National Institute of Child Health \& Human Development (NICHD), National Institutes of Health (NIH), Bethesda, MD, USA.

\section{Patient consent}

Written informed consent has been obtained from all patients for publication of the submitted article and accompanying images.

\section{Author contribution statement}

All authors contributed equally.

\section{References}

1 Assié G, Libé R, Espiard S, Rizk-Rabin M, Guimier A, Luscap W, Barreau O, Lefèvre L, Sibony M, Guignat L, et al. ARMC5 mutations in macronodular adrenal hyperplasia with Cushing's syndrome. New England Journal of Medicine 2013369 2105-2114. (https://doi. org/10.1056/NEJMoa1304603)

2 De Venanzi A, Alencar GA, Bourdeau I, Fragoso MCBV \& Lacroix A. Primary bilateral macronodular adrenal hyperplasia. Current Opinion in Endocrinology, Diabetes, and Obesity 201421 177-184. (https://doi org/10.1097/MED.0000000000000061)

3 Hsiao HP, Kirschner LS, Bourdeau I, Keil MF, Boikos SA, Verma S, Robinson-White AJ, Nesterova M, Lacroix A \& Stratakis CA. Clinical and genetic heterogeneity, overlap with other tumor syndromes, and atypical glucocorticoid hormone secretion in adrenocorticotropinindependent macronodular adrenal hyperplasia compared with other adrenocortical tumors. Journal of Clinical Endocrinology and Metabolism 200994 2930-2937. (https://doi.org/10.1210/jc.20090516)

4 Lacroix A, Bourdeau I, Lampron A, Mazzuco TL, Tremblay J \& Hamet P. Aberrant G-protein coupled receptor expression in relation to adrenocortical overfunction. Clinical Endocrinology 201073 1-15. (https://doi.org/10.1111/j.1365-2265.2009.03689.x)

5 Berthon A, Faucz FR, Espiard S, Drougat L, Bertherat J \& Stratakis CA. Age-dependent effects of Armc5 haploinsufficiency on adrenocortical function. Human Molecular Genetics 201726 3495-3507. (https://doi. org/10.1093/hmg/ddx235)

6 Hannah-Shmouni F, Moraitis AG, Romero VV, Faucz FR, Mastroyannis SA, Berthon A, Failor RA, Merino M, Demidowich AP \& Stratakis CA. Successful treatment of estrogen excess in primary bilateral macronodular adrenocortical hyperplasia with leuprolide acetate. Hormone and Metabolic Research 201850 124-132. (https:// doi.org/10.1055/s-0043-122074)

7 Swain JM, Grant CS, Schlinkert RT, Thompson GB, VanHeerden JA, Lloyd RV \& Young WF. Corticotropin-independent macronodular adrenal hyperplasia: a clinicopathologic correlation. Archives of Surgery 1998133 541-545; discussion 545. (https://doi.org/10.1001/ archsurg.133.5.541) 
8 Spencer SJ, Rabinovici J, Mesiano S, Goldsmith PC \& Jaffe RB. Activin and inhibin in the human adrenal gland: regulation and differential effects in fetal and adult cells. Journal of Clinical Investigation 199290 142-149. (https://doi.org/10.1172/JCI115827)

9 Shearer JL, Salmons N, Murphy DJ \& Gama R. Postmenopausal hyperandrogenism: the under-recognized value of inhibins. Annals of Clinical Biochemistry 201754 174-177. (https://doi. org/10.1177/0004563216656873)

10 Farnworth PG, Wang Y, Leembruggen P, Ooi GT, Harrison C, Robertson DM \& Findlay JK. Rodent adrenocortical cells display high affinity binding sites and proteins for inhibin A, and express components required for autocrine signalling by activins and bone morphogenetic proteins. Journal of Endocrinology 2006188 451-465. (https://doi.org/10.1677/joe.1.06444)

11 Fogt F, Zimmerman RL, Mulligan N, Vortmeyer AO, Poremba C, Harris CA, Alsaigh N, Tomaszewski JE \& Nikulasson ST. BCL-2 expression and inhibin-A in adrenal neoplasms: a comparative study. International Journal of Molecular Medicine 19993 271-274. (https:// doi.org/10.3892/ijmm.3.3.271)
12 Berthon A, Hannah-Shmouni F, Maria AG, Faucz FR \& Stratakis CA. High expression of adrenal P450 aromatase (CYP19A1) in association with ARMC5-primary bilateral macronodular adrenocortical hyperplasia. Journal of Steroid Biochemistry and Molecular Biology 2019191 105316. (https://doi.org/10.1016/j. jsbmb.2019.02.011)

13 Nieman LK, Biller BMK, Findling JW, Newell-Price J, Savage MO, Stewart PM \& Montori VM The Diagnosis of Cushing's Syndrome: An Endocrine Society Clinical Practice Guideline. Journal of Clinical Endocrinology \& Metabolism 200893 1526-1540. (https://doi. org/10.1210/jc.2008-0125)

14 Stratakis CA \& Kirschner LS. Clinical and genetic analysis of primary bilateral adrenal diseases (micro- and macronodular disease) leading to Cushing syndrome. Hormone and Metabolic Research 199830 456-463. (https://doi.org/10.1055/s-2007-978914)

15 Hofland J, Feelders RA, Van Der Wal R, Kerstens MN, Haak HR, De Herder WW \& de Jong FH. Serum inhibin pro- $\alpha \mathrm{C}$ is a tumor marker for adrenocortical carcinomas. European Journal of Endocrinology 2012 166 281-289. (https://doi.org/10.1530/EJE-11-0693)

Received in final form 4 March 2020 Accepted 7 April 2020 